Vietnam Journal of Mechanics, VAST, Vol. 28, No.4 (2006), pp. 197-206

\title{
NON-LINEAR ANALYSIS ON STABILITY OF CORRUGATED CROSS-PLY LAMINATED COMPOSITE PLATES
}

\author{
Dao Huy Bich ${ }^{1}$ And Khuc Van PhU ${ }^{2}$ \\ 1 Vietnam National University, Hanoi \\ ${ }^{2}$ Military Logistic Academy
}

\begin{abstract}
In the present paper the governing equations for corrugated cross-ply laminated composite plates in the form of a sine wave are developed based on the Kirchoff-Love's theory. and the extension of Seydel's technique. By using Bubnov-Galerkin method approximated analytical solutions to the non-linear stability problem of corrugated laminated composite plates subjected to biaxial loads are investigated. The post buckling load-deflection curve of corrugated plates and analytical expressions of the upper and lower buckling loads are presented. The effectiveness of corrugated plates in enhancing the stability compared with corresponding flat plates is given.
\end{abstract}

\section{INTRODUCTION}

Laminated composite plates and shells are widely used as basic structure components and their static and dynamic problems with geometrical non-linearity are of significant practical interest, particularly stability and post-buckling behavior of composite plates and shells is more important. Investigated results in this problem of flat laminated composite plates have been received by many authors $[1,3,6,7,9,10,11,13]$. However, the analysis of corrugated laminated composite plates has received comparitively little attention.

Corrugated plates of wave form made of isotropic elastic material were considered as flat orthotropic plates with corresponding orthotropic constants determined by the Seydel's technique. This approach was acceptable to solve many bending and stability problems of corrugated plates in practice $[5,8,12]$. In paper [4] the authors developed the Seydel's technique to the bending problems of corrugated cross-ply laminated composite plates and cylindrical shells. But for the stability problems, besides bending stiffnesses we need to formulate extensional stiffnesses of corrugated cross-ply laminated composite plates.

Consequently, the purpose of the present paper is to formulate the constitutive equations of corrugated cross-ply laminated composite plates of wave form by using the Seydel's technique and investigate the non-linear stability problems of corrugated composite plates subjected to biaxial compressive loads.

\section{GOVERNING EQUATIONS}

Consider a rectangular symmetrically laminated composite corrugated plate in the form of a sine wave (see Fig. 1), each layer of which is an unidirectional composite material. The plate is subjected to biaxial compressive loads of intensities $\mathrm{p}$ and $\mathrm{q}$ respectively, where 
$p$ and $q$ vary arbitrarily. Suppose the portion of cross-section line of the corrugated plate in the plane $(x, z)$ has the form of a sine wave (Fig. 1)

$$
z=H \sin \frac{\pi x}{l}
$$

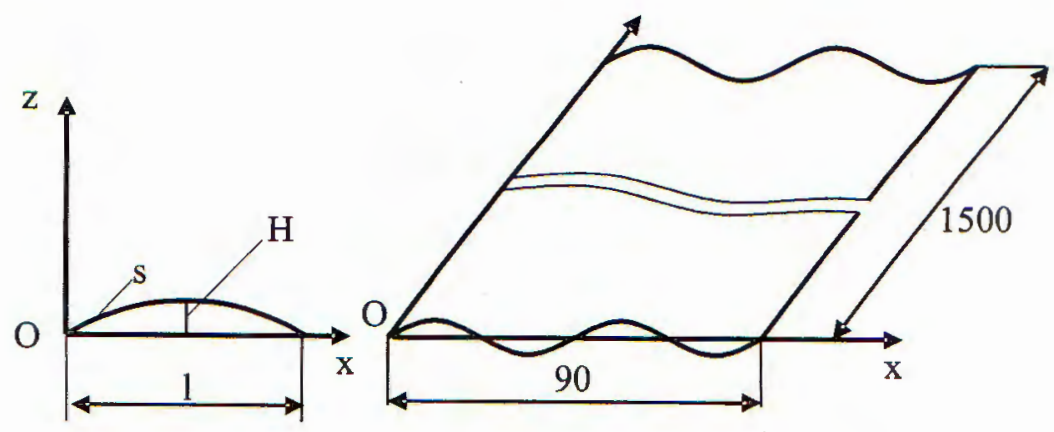

Fig. 1. Model of corrugated plate

Non-linear strain-displacement relationships in the middle surface for a such corrugated plate are:

$$
\begin{aligned}
& \varepsilon_{1}^{0}=\frac{\partial u}{\partial x}+\frac{1}{2}\left(\frac{\partial w}{\partial x}\right)^{2}-k w \\
& \varepsilon_{2}^{0}=\frac{\partial v}{\partial y}+\frac{1}{2}\left(\frac{\partial w}{\partial y}\right)^{2} \\
& \varepsilon_{6}^{0}=\left(\frac{\partial u}{\partial y}+\frac{\partial v}{\partial x}\right)+\frac{\partial w}{\partial x} \frac{\partial w}{\partial y}
\end{aligned}
$$

where $u, v$ and $w$ denote displacements of the middle surface point along $x, y$ and $z$ directions respectively, $\varepsilon_{i}^{o}(i=1,2$ and 6$)$ are strains in the middle surface; $k$ is the curvature of the portion line in $(x, z)$ plane, which is defined as:

$$
k=\frac{z^{\prime \prime}}{\left(1+z^{\prime 2}\right)^{\frac{3}{2}}} \approx z^{\prime \prime}=-H \frac{\pi^{2}}{l^{2}} \sin \frac{\pi x}{l}
$$

The constitutive stress - strain relations for the plate material are omitted here for brevity [see Reddy 11]. However note that in a multilayered symmetrically laminated material the coupling stiffnesses are equal to zero, while the extensional stiffnesses $A_{16}$ and $A_{26}$ are negligible compared to the others. This means that the constitutive equations are indentical to those for a specially orthotropic material. Then integrating the stress -strain equations through the thickness of the plate we obtain the expressions for stress 
resultants:

$$
\begin{aligned}
& N_{1}=A_{11}\left[\frac{\partial u}{\partial x}+\frac{1}{2}\left(\frac{\partial w}{\partial x}\right)^{2}-k . w\right]+A_{12}\left[\frac{\partial u}{\partial y}+\frac{1}{2}\left(\frac{\partial w}{\partial y}\right)^{2}\right] \\
& N_{2}=A_{12}\left[\frac{\partial u}{\partial x}+\frac{1}{2}\left(\frac{\partial w}{\partial x}\right)^{2}-k \cdot w\right]+A_{22}\left[\frac{\partial v}{\partial y}+\frac{1}{2}\left(\frac{\partial w}{\partial y}\right)^{2}\right] \\
& N_{6}=A_{66}\left(\frac{\partial u}{\partial y}+\frac{\partial v}{\partial x}+\frac{\partial w}{\partial x} \frac{\partial w}{\partial y}\right)
\end{aligned}
$$

where $A_{i j}(i, j=1,2$ and 6$)$ are extensional stiffnesses of the plate.

About the changes of curvature and twist of a corrugated plate in reality it is a very complicated problem, but with the condition restrained on the form of corrugated plate, where $H<<l$ we can apply the Seydel's technique into consideration. Suppose that the changes of curvature and twist of a corrugated plate are the same as of a flat one, i.e.

$$
\chi_{x}=-\frac{\partial^{2} w}{\partial x^{2}}, \quad \chi_{y}=-\frac{\partial^{2} w}{\partial y^{2}}, \quad \chi_{x y}=-2 \frac{\partial^{2} w}{\partial x \partial y},
$$

but the bending stiffnesses of a corrugated composite plate $D_{i j}^{*}(i, j=1,2$ and 6$)$ are determined by the extension of Seydel's technique [4] as follows:

$$
D_{11}^{*}=\frac{l}{s} D_{11} ; \quad D_{22}^{*}=E_{2} I ; \quad D_{3}^{*}=\left(D_{12}^{*}+2 D_{66}^{*}\right)=\frac{l}{s}\left(D_{12}+2 D_{66}\right)
$$

where $D_{i j}(i, j=1,2$ and 6$)$ are bending stiffnesses of the corresponding flat plate;

$$
I=\frac{h H^{2}}{2}\left[1-\frac{0.81}{1+2.5\left(\frac{H}{2 l}\right)^{2}}\right]
$$

where:

$E_{2}$ - the effective modulus in the y direction,

$h$ - the plate thickness,

$s$ - the length of a portion of corrugated line (Fig. 1),

$$
s=\int_{0}^{l} \sqrt{1+\frac{\pi^{2} H^{2}}{l^{2}} \cos ^{2} \frac{\pi x}{l}} d x \approx l \sqrt{1+\frac{\pi^{2} H^{2}}{2 l^{2}}} \approx l\left(1+\frac{\pi^{2} H^{2}}{4 l^{2}}\right)
$$

It is recommended [5] that these constants be determined by experimentation whenever possible, but can be used successfully in practice.

In the results the internal moment resultants of a corrugated composite plate of wave form are: 


$$
\begin{aligned}
& M_{1}=-\left(D_{11}^{*} \frac{\partial^{2} w}{\partial x^{2}}+D_{12}^{*} \frac{\partial^{2} w}{\partial y^{2}}\right), \\
& M_{2}=-\left(D_{12}^{*} \frac{\partial^{2} w}{\partial x^{2}}+D_{22}^{*} \frac{\partial^{2} w}{\partial y^{2}}\right), \\
& M_{66}=-2 D_{66}^{*} \frac{\partial^{2} w}{\partial x \partial y}
\end{aligned}
$$

The equations of equilibrium of a plate subjected to uniformly distributed biaxial compressive loads of intensities $\mathrm{p}$ and $\mathrm{q}$ respectively, according to [2], when considering the non-linear geometry are of the form:

$$
\begin{gathered}
\frac{\partial N_{1}}{\partial x}+\frac{\partial N_{6}}{\partial y}=0 \\
\frac{\partial N_{6}}{\partial x}+\frac{\partial N_{2}}{\partial y}=0 \\
\frac{\partial^{2} M_{1}}{\partial x^{2}}+2 \frac{\partial^{2} M_{6}}{\partial x \partial y}+\frac{\partial^{2} M_{2}}{\partial y^{2}}+N_{1} \frac{\partial^{2} w}{\partial x^{2}}+2 N_{6} \frac{\partial^{2} w}{\partial x \partial y}+N_{2} \frac{\partial^{2} w}{\partial y^{2}}+p \frac{\partial^{2} w}{\partial x^{2}}+q \frac{\partial^{2} w}{\partial y^{2}}=0
\end{gathered}
$$

The substitution of equations (2.3) and (2.4) into (2.4) yields the system of equations of equilibrium in terms of displacements

$$
\begin{aligned}
& A_{11} \frac{\partial^{2} u}{\partial x^{2}}+A_{66} \frac{\partial^{2} u}{\partial y^{2}}+\left(A_{12}+A_{66}\right) \frac{\partial^{2} v}{\partial x \partial y}+A_{11} \frac{\partial w}{\partial x} \frac{\partial^{2} w}{\partial x^{2}}+A_{66} \frac{\partial w}{\partial x} \frac{\partial^{2} w}{\partial y^{2}} \\
& +\left(A_{12}+A_{66}\right) \frac{\partial w}{\partial y} \frac{\partial^{2} w}{\partial x \partial y}-A_{11}\left(w \frac{\partial k}{\partial x}+k \frac{\partial w}{\partial x}\right)=0 \\
& A_{22} \frac{\partial^{2} v}{\partial y^{2}}+A_{66} \frac{\partial^{2} v}{\partial x^{2}}+\left(A_{12}+A_{66}\right) \frac{\partial^{2} u}{\partial x \partial y}+A_{22} \frac{\partial w}{\partial y} \frac{\partial^{2} w}{\partial y^{2}}+A_{66} \frac{\partial w}{\partial y} \frac{\partial^{2} w}{\partial x^{2}} \\
& +\left(A_{12}+A_{66}\right) \frac{\partial w}{\partial x} \frac{\partial^{2} w}{\partial x \partial y}-A_{12}\left(w \frac{\partial k}{\partial y}+k \frac{\partial w}{\partial y}\right)=0 \\
& D_{11}^{*} \frac{\partial^{4} w}{\partial x^{4}}+2\left(D_{12}^{*}+2 D_{66}^{*}\right) \frac{\partial^{4} w}{\partial x^{2} \partial y^{2}}+D_{22}^{*} \frac{\partial^{4} w}{\partial y^{4}}-\frac{1}{2} A_{11}\left(\frac{\partial w}{\partial x}\right)^{2} \frac{\partial^{2} w}{\partial x^{2}} \\
& -\frac{1}{2} A_{12}\left(\frac{\partial w}{\partial y}\right)^{2} \frac{\partial^{2} w}{\partial x^{2}}-\frac{1}{2} A_{12}\left(\frac{\partial w}{\partial x}\right)^{2} \frac{\partial^{2} w}{\partial y^{2}}-\frac{1}{2} A_{22}\left(\frac{\partial w}{\partial y}\right)^{2} \frac{\partial^{2} w}{\partial y^{2}} \\
& -A_{11} \frac{\partial u}{\partial x} \frac{\partial^{2} w}{\partial x^{2}}-A_{12} \frac{\partial u}{\partial x} \frac{\partial^{2} w}{\partial y^{2}}-2 A_{66} \frac{\partial u}{\partial y} \frac{\partial^{2} w}{\partial x \partial y}-2 A_{66} \frac{\partial^{2} w}{\partial x \partial y} \frac{\partial w}{\partial x} \frac{\partial w}{\partial y} \\
& -A_{66} \frac{\partial v}{\partial y} \frac{\partial^{2} w}{\partial x^{2}}-A_{22} \frac{\partial v}{\partial y} \frac{\partial^{2} w}{\partial y^{2}}-2 A_{66} \frac{\partial v}{\partial x} \frac{\partial^{2} w}{\partial x \partial y} \\
& +A_{11} k w \frac{\partial^{2} w}{\partial x^{2}}+A_{12} k w \frac{\partial^{2} w}{\partial y^{2}}-p \frac{\partial^{2} w}{\partial x^{2}}-q \frac{\partial^{2} w}{\partial y^{2}}=0
\end{aligned}
$$


The plate considered in the following analysis is simply supported, thus the boundary conditions are:

$$
\begin{aligned}
& w=0, \quad v=0, \quad M_{1}=0 \quad \text { at } \quad x=0 \text { and } \quad x=a \\
& w=0, \quad u=0, \quad M_{2}=0 \text { at } y=0 \text { and } y=b
\end{aligned}
$$

where $a$ and $b$ are lengths of plate edges.

An approximation is acceptable in the vicinity of the buckling loads, so that the buckling mode shape is represented by a single term of a double Fourier series. The boundary conditions (2.6) discussed here can be satisfied if the buckling mode shape is represented by:

$$
\begin{aligned}
u & =U_{m n} \cos \frac{m \pi x}{a} \sin \frac{n \pi y}{b}, \\
v & =V_{m n} \sin \frac{m \pi x}{a} \cos \frac{n \pi y}{b}, \\
w & =W_{m n} \sin \frac{m \pi x}{a} \sin \frac{n \pi y}{b}
\end{aligned}
$$

where $m, n$ are natural numbers representing the number of half waves in the $x$ and $y$ directions respectively.

Substituting expressions (2.7) into the equations of equilibrium (2.5) and applying the Bubnox-Galerkin procedure yield the set of three algebraic equations with respect to the amplitudes $\mathrm{U}_{m n}, \mathrm{~V}_{m n}, \mathrm{~W}_{m n}$. The first two equations of this set are linear algebraic equations for $\mathrm{U}_{m n}, \mathrm{~V}_{m n}$ :

$$
\begin{aligned}
& a_{1} U_{m n}+a_{2} V_{m n}=a_{3} W_{m n}+a_{4} W_{m n}^{2}, \\
& a_{5} U_{m n}+a_{6} V_{m n}=a_{7} W_{m n}+a_{8} W_{m n}^{2}
\end{aligned}
$$

so that the amplitudes of the in-plane displacements can be expressed in terms of $W_{m n}$. When these expressions are substituted into the remaining equation of equilibrium, the result is a non-linear algebraic equation with respect to $W_{m n}$ that can be represented in the form

$$
a_{9} W_{m n}^{3}+a_{10} W_{m n}^{2}+\left(a_{11}+R\right) W_{m n}=0
$$

where $a_{i}(i=1,2, \ldots, 11)$ and $R$ are coefficients which depend on the material, geometry and buckling mode shape:

$$
\begin{aligned}
& a_{1}=\frac{1}{4} \frac{\left(m^{2} \pi^{2} b^{2} A_{11}+n^{2} \pi^{2} a^{2} A_{66}\right)}{a b}, \\
& a_{2}=\frac{1}{4} m n \pi^{2}\left(A_{12}+A_{66}\right), \\
& a_{3}=\frac{H \pi^{2} m a b A_{11}}{l\left(4 m^{2} l^{2}-a^{2}\right)}+\frac{H \pi^{2} m b\left(a^{2}-2 m^{2} l^{2}\right) A_{66}}{a l\left(a^{2}-4 m^{2} l^{2}\right)} \\
& a_{4}=-\left[\frac{8 b \pi m^{2} A_{11}}{a^{2} n}+\frac{8 n \pi A_{66}}{b}-\frac{4}{9} \frac{n \pi\left(A_{12}+A_{66}\right)}{b}\right] \\
& a_{5}=\frac{1}{4} m n \pi^{2}\left(A_{12}+A_{66}\right), \\
& a_{6}=\frac{1}{4}\left[\frac{n^{2} \pi^{2} a^{2} A_{22}+m^{2} \pi^{2} b^{2} A_{66}}{a b}\right],
\end{aligned}
$$




$$
\begin{aligned}
a_{7}= & \frac{H n \pi^{2}\left(a^{2}-2 m^{2} l\right) A_{12}}{l\left(a^{2}-4 m^{2} l^{2}\right)}, \\
a_{8}= & -\left[\frac{8}{9} \frac{a n^{2} \pi A_{22}}{m b^{2}}+\frac{8}{9} \frac{m \pi A_{66}}{a}-\frac{4}{9} \frac{m \pi\left(A_{12}+A_{66}\right)}{a}\right], \\
a_{9}= & \frac{3 \pi^{4}}{64 a^{3} b^{3}}\left[m^{4} b^{4} A_{11}+2 m^{2} n^{2} a^{2} b^{2} A_{12}+n^{4} a^{4} A_{22}\right] \\
& -\frac{16 \pi}{9 a^{2} n b}\left[m^{2} b^{2} A_{11}+a^{2} n^{2}\left(A_{12}+2 A_{66}\right)\right] \frac{\left(a_{4} a_{6}-a_{2} a_{8}\right)}{a_{1} a_{6}-a_{2} a_{5}} \\
& -\frac{16 \pi}{9 a b^{2} m}\left[b^{2} m^{2}\left(A_{12}+2 A_{66}\right)+a^{2} n^{2} A_{22}\right] \frac{\left(a_{1} a_{8}-a_{4} a_{5}\right)}{a_{1} a_{6}-a_{2} a_{5}}, \\
a_{10}= & -\frac{16 \pi}{9 a^{2} n b}\left[m^{2} b^{2} A_{11}+a^{2} n^{2}\left(A_{12}+2 A_{66}\right)\right] \frac{\left(a_{3} a_{6}-a_{2} a_{7}\right)}{a_{1} a_{6}-a_{2} a_{5}} \\
& -\frac{16 \pi}{9 a b^{2} m}\left[b^{2} m^{2}\left(A_{12}+2 A_{66}\right)+a^{2} n^{2} A_{22}\right] \frac{\left(a_{1} a_{7}-a_{3} a_{5}\right)}{a_{1} a_{6}-a_{2} a_{5}}, \\
a_{11}= & \frac{1}{4} \frac{\pi^{4}}{a^{3} b^{3}}\left[m^{4} b^{4} D_{11}^{*}+2 m^{2} n^{2} a^{2} b^{2}\left(D_{12}^{*}+2 D_{66}^{*}+n^{4} a^{4} D_{22}^{*}\right)\right] \\
R= & \frac{1}{4} \frac{\pi^{2}}{a b}\left(m^{2} b^{2} p+n^{2} a^{2} q\right)
\end{aligned}
$$

Note that a similar equation can be obtained for other boundary conditions as long as the plate is modeled as a single degree of freedom system, i.e. a single Fourier term is retained in each displacement component, of course, with other appropriate functions.

Taking $W_{m n} \neq 0$, i.e. considering the plate after the lost of stability we obtain

$$
a_{9} W_{m n}^{2}+a_{10} W_{m n}^{+} a_{11}+R=0
$$

Because the plate is working in the elastic stage, so in the case of simultaneous action of forces $p$ and $q$ we can set $q=\alpha p$, the equation (2.11) can be rewritten

$$
f=a_{9} W_{m n}^{2}+a_{10} W_{m n}^{+} a_{11}+\frac{1}{4} \frac{\pi^{2}}{a b}\left(m^{2} b^{2}+\alpha n^{2} a^{2}\right) p=0
$$

Substituting $W_{m n}=0$ in equation (2.12) yields the value of critical load $p$

$$
p=-\frac{4 a b \cdot a_{11}}{\pi^{2}\left(m^{2} b^{2}+\alpha n^{2} a^{2}\right)}
$$

or $\quad p_{\text {upper }}=\frac{\pi^{2}\left(m^{4} D_{11}^{*} \lambda^{4}+2 m^{2} n^{2} \lambda^{2}\left(D_{12}^{*}+2 D_{66}^{*}\right)+n^{4} D_{22}^{*}\right)}{b^{2}\left(m^{2} \lambda^{2}+n^{2} \alpha\right)}$, where $\lambda=\frac{b}{a}$, that is called the upper buckling load, which coincides with the linear buckling load. Then the critical load $\mathrm{q}$ is determined by $q_{\text {upper }}=\alpha p_{\text {upper }}$.

The lower buckling load of the corrugated composite plate can be obtained from equation (2.12) by using the condition

$$
\frac{d f}{d W_{m n}}=0
$$

The value of $W_{m n}$ corresponding to the lower buckling load is found from this equation 


$$
W_{m n}^{0}=-\frac{a_{10}}{2 a_{9}}
$$

and substituted into equation (2.12) yielding

$$
p_{\text {lower }}=-\frac{4 a b}{\pi^{2}\left(m^{2} b^{2}+\alpha n^{2} a^{2}\right)}\left(a_{11}-\frac{a_{10}^{2}}{4 a_{9}}\right)
$$

The sign "minus" indicates that the load $p$ is compressive. Numbers $m, n$ must be chosen such that the absolute value of the critical buckling load $p$ is minimum.

The post-buckling load-deflection curve (2.12) is illustrated in the Fig. 2

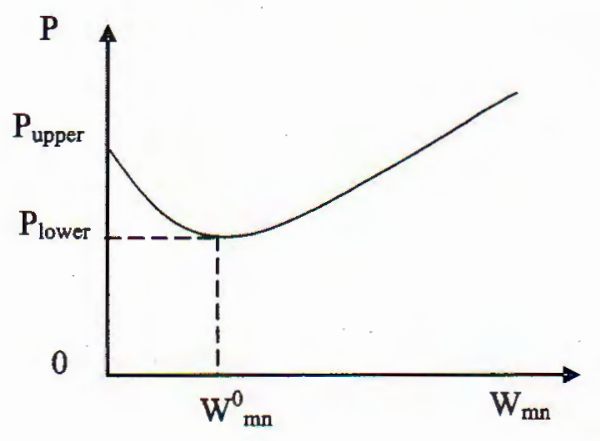

Fig. 2. Post-buckling load-deflection curve of the plate

The domain limited by the upper and lower buckling loads is called the unstable domain of the corrugated plate. Thus permissible loads have to be chosen such that the safety is provided according to the lower critical load.

Remark. From the equation (2.12) we can see that post-buckling behaviour of flat and corrugated composite plates are different. A corrugated composite plate becomes a flat one when $l=s, H \rightarrow 0$, stiffnesses $D_{i j}^{*}$ will tend to $D_{i j}$, the coefficients in $(2.10) a_{3}=a_{7}=$ 0 and $a_{10}=0$, at that time the equation (2.12) representing a post-buckling load deflection curve has following character: gradually increasing the active load leads to increasing the deflection, the critical load is

$$
p_{c r}=\frac{\pi^{2}\left(m^{4} D_{11} \lambda^{4}+2 m^{2} n^{2} \lambda^{2}\left(D_{12}+2 D_{66}\right)+n^{4} D_{22}\right)}{b^{2}\left(m^{2} \lambda^{2}+n^{2} \alpha\right)}
$$

and there isn't an unstable domain, while for a corrugated composite plate there exists an unstable domain. When analysing reinforced composite plates [7] also occurs such behavior. 


\section{NUMERICAL EXAMPLES}

Let's consider a simply supported rectangular corrugated symmetrically laminated plate in the form of a sine wave with $a=0.9 \mathrm{~m}, b=1.5 \mathrm{~m}, H=0.03 \mathrm{~m}, l=0.09 \mathrm{~m}$ and $s=0.112 \mathrm{~m}$. The skin of the plate had 6 plies [45/-45/90/90/-45/45], each ply being 0.5 mim thick. The material of the plates considered in the following examples had Thornel 300 graphite fibers and Narmco 5208 thermosetting epoxy resin [6]. The properties of this material are $E_{1}=127.4 \mathrm{GPa}, E_{2}=13.0 \mathrm{GPa}, G_{12}=6.4 \mathrm{GPa}, \nu_{12}=0.38$.

Some numerical results are shown in the Fig. 3, 4 and 5. Relation between the critical buckling load and the dimension ratio of corrugated composite plate subjected to a compressive load in the y direction is illustrated in Fig. 3.

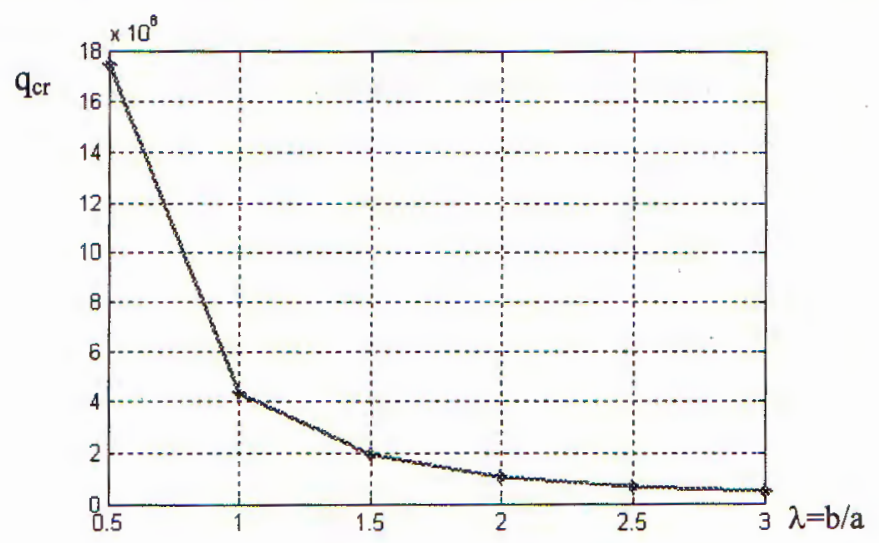

Fig. 3. Effect of the plate dimension ratio on bucking loads

The effect of the plate thickness on critical load for a corrugated composite plate subjected to uniaxial and biaxial loads (with $\alpha=1$ ) is shown in Fig. 4a and for a flat one in Fig. 4b.

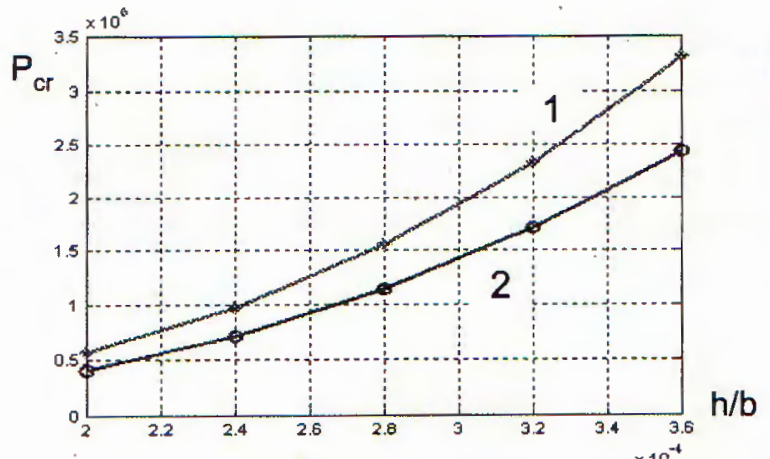

a.

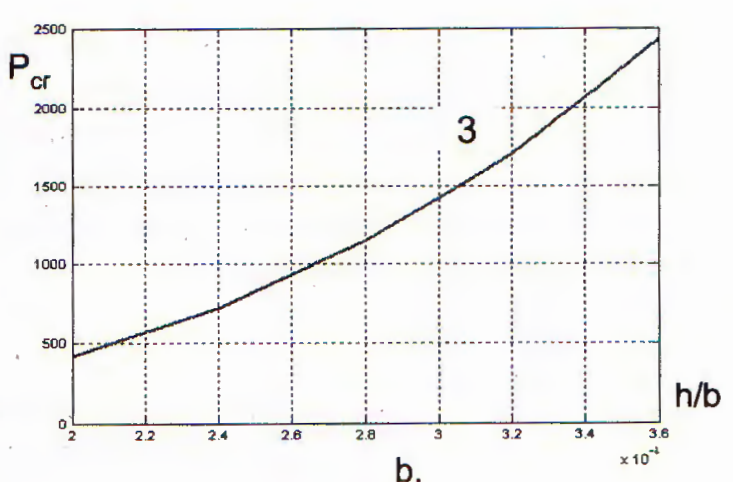

b.

Fig. 4. Effect of the plate thickness on buckling load 1.uniaxial load; 2. biaxial load; 3. flat plate

The effect of the height $H$ of portion line on critical loads of a corrugated composite plate subjected to compressive load in the $x$ direction is presented in Fig. 5. 


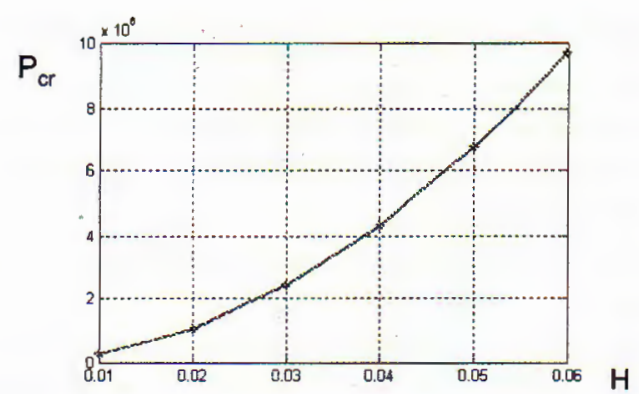

Fig. 5. Effect of the height $\mathrm{H}$ on buckling loads

From these figures it is clear that the corrugated composite plates significantly increase the buckling loads. A similar conclusion follows for corrugated plates of wave form with greater height $H$. But the buckling loads decrease for longer plate in the $y$ direction, when they are subjected to axial compressive load in the same direction. The wave form of corrugated laminated composite plate provides a higher stability of plates, it is why corrugated composite plates of wave form are more useful in practice.

\section{CONCLUSION}

The governing equations for corrugated cross-ply laminated composite plates have been derived based on the extension of Seydel's technique. These equations can be used to non-linear analysis of static and dynamic problems of corrugated laminated composite plates. The approach to considering stability problems presented in this paper allows to obtain analytical expressions of critical buckling loads of corrugated plates subjected to biaxial compressive loads.

The effectiveness of corrugated composite plates in enhancing the stability compared with corresponding flat plates is illustrated.

This publication is partly supported by the National Council for Natural Sciences.

\section{REFERENCES}

1. E. J. Barbero, J. N. Reddy Non-linear analysis of composite laminated using a generalized laminate plate theory, A/AA Journal 28 (11) (1990) 1987-1994.

2. D. O. Brush, B.O. Almroth, Buckling of Bars, Plates and Shell, Mc Graw-Hill, 1975.

3. C. T. Chia, M. K. Prabhakara, Large deflection of unsymmetric cross-ply and angleply plates, Journal of Mechanical Engineering Science 18(4), 1976, pp.179-183.

4. Dao H. B., Vu K. B., Dao V. D., Tran I. T., Pham C. V., Calculation of the goffered multilayered composite cylindrical shells, Journal of Mechanics, NCNST of Vietnam, 19(3), (1997) 9-18 (in Vietnamese).

5. David Mc Farland et al. Analysis of plates, Spartan Books, New York 1972.

6. N. F. Jr. Knight, J. I. L. Starnes, Post-buckling behaviours of selected curved stifffened graphite - epoxy panels loaded in axial compression. AIAA Journal 26 (1988) 344352 .

7. Khuc Van Phu, Reseach on non-linear multilayered laminated CPS plates, Ph. D. Thesis, Hanoi 2005.

8. S. G. Lechnitsky, Anisotropic plates, $2^{\text {nd }}$ edition Moscow 1957. 
9. C. L. Liao, J. N. Reddy, Analysis of anisotropic stiffened composite laminates using continuum-based shell element, Computer and Structures, 34 (6) (1990) 805-815.

10. N. S. Putcha, J. N. Reddy, Stability and natural vibration analysis of laminated plates using a mixed element based on a refined plate theory. Joumal of Sound and Vibration, 104 (2) (1986) 285-300.

11. J. N. Reddy, Mechanics of Laminated Composite Plates and Shells: Theory and analysis, $2^{\text {nd }}$ edition, CRC Press 2004.

12. E. Seydel, Schubknickversuche mit Welblechtafeln, DVL - Bericht, 1931.

13. S. A. Zaghloul, J. B. Kennedy, Nonlinear behavior of symmetrically laminated plates, Journal of Applied Mechanics, 42 (1975) 234-236.

Received September 18, 2006

\section{PHÂN TÍCH PHI TUYẾN VỀ ÔN DINH CƯA TÂMM COMPOSITE LỚP LƯợN SÓNG}

Trong bài báo này đã thiết lập các phương trình cơ sớ của tấm composite lớp lượn sóng dựa trên lý thuyết Kirchff-Love và mở rộng cách tiếp cận Seydel. Sứ dụng phương pháp Bubnov-Galerkin vào xác định nghiệm giải tích gần đúng của bài toán ổn định phi tuyến của tấm composite lượn sóng chịu nén theo hai phương. Đã nhận được dường tải - độ võng sau tới hạn và biểu thươ giải tích của lực tới hạn trên và dưới. Đã chì ra hiệu qưa tăng ổn định cứa tấm lượn sóng so với tấm phẳng tương ứng. 